To appear in Lingua.

\title{
Deriving Natural Classes in Phonology
}

\author{
Edward Flemming
}

Department of Linguistics,

Stanford University,

Building 460,

Stanford, CA 94305-2150

\author{
Tel: +1-650-723-8120 \\ fax: +1-650-723-5666 \\ E-mail address: flemming@stanford.edu
}




\begin{abstract}
It is one of the most basic generalizations in phonology that only certain sets of sounds pattern together in phonological processes. These sets are referred to as natural classes. This paper develops a new analysis of the natural class generalization, formulated in terms of Optimality Theory. It is shown that natural classes derive from the nature of the set of markedness constraints. For example, sounds can pattern together as a natural class if they violate markedness constraints in the same environment, so given constraints *XA and $* \mathrm{XB}, \mathrm{A}$ and $\mathrm{B}$ can form a natural class. As a result the range of possible natural classes depends on the inventory of constraints, not on the feature set. This analysis is shown to have empirical advantages over the standard account according to which natural classes are characterized purely in terms of features.
\end{abstract}

Keywords: phonological features, natural classes, Optimality Theory. 


\section{Introduction}

It is one of the most basic generalizations in phonology that only certain sets of sounds pattern together in phonological processes, and that these sets can be characterized in terms of shared phonetic properties. For example, Kenstowicz and Kisseberth (1977) write that 'sets like [p, t, k], [m, n, n, y], and [i, e, ä] are classes of sounds that appear together in rule after rule; sets like [e, x, n], [?, r, f, $\mathrm{w}]$, or [a, s, b] are rarely (if ever) found in any rules in any language.' (p.22). The widely attested sets are referred to as natural classes. It has been observed that natural classes can generally be given simple phonetic characterizations, e.g. [p, t, $\mathrm{k}]$ are voiceless stops, [m, n, $\mathrm{\eta}, \mathrm{\eta}]$ are nasal stops, and [i, e, ä] are front vowels. By contrast, Kenstowicz and Kisseberth's examples of unnatural classes consist of phonetically disparate sounds.

The standard theoretical account of this natural class generalization is formulated within a rule-based framework, such as that developed in Chomsky and Halle (1968). In this model, a rule takes the form shown in (1). The natural class generalization is accounted for by constraining rules to refer only to natural classes of sounds. That is, the set of sounds that undergo the rule, specified to the left of the arrow, must be a natural class, and any sets of sounds referred to in the environment of the rule must be natural classes.

$$
\left[\begin{array}{c}
\text {-cont } \\
- \text { son }
\end{array}\right] \rightarrow[+ \text { voice }] /[+ \text { nasal }]_{-}
$$


The task of characterizing which sets of sounds constitute natural classes falls to the feature theory; indeed this is usually taken to be one of the fundamental roles of feature theory. A natural class is claimed to be a set of sounds that can be specified by a conjunction of feature values. So the rule in (1) refers to three natural classes: the set of segments that undergo the rule is the set of stops, which is a natural class because it can be characterized in terms of two feature specifications, [-continuant] and [-sonorant], and the environment mentions the natural class of nasal sounds, characterized by the feature [+nasal], finally, the structural change adds the feature [+voice], so the segments that undergo the rule are mapped onto a natural class, in this case the voiced stops, [-continuant, sonorant, +voice] (cf. Kenstowicz and Kisseberth, 1977: 240).

Sounds do not constitute a natural class just because they share feature specifications, the class must contain all the sounds that have those feature specifications. For example, given the vowels and feature specifications shown in (2), the set $[i, e, o, u]$ is a natural class according to the feature-based definition, since it can be specified by the feature [-low]. The sets [e, u] and [i, u, a] are unnatural classes because these sets of vowels do not share any set of feature specifications that are not shared with any of the other vowels. The vowels [e, u] are both [-low], but they do not constitute a natural class because there are other [low] vowels, [i, o]. Given this definition, the basic claim of the standard account of the natural class generalization is that phonological rules may refer to classes like $[i, e, o, u]$, but not to classes like $[e, u]$ or $[i, u, a]$. 


$\begin{array}{lllll}\text { [+high }] & \text { i } & & \text { u } & \\ \text { [-high }] & \text { e } & & \text { o } & \text { [-low }] \\ & & & & {[+ \text { low }]}\end{array}$

This standard theory of natural classes turns out to be highly problematic. I will review these problems, then propose an alternative analysis of the natural class generalization, formulated in terms of Optimality Theory (Prince and Smolensky, 1993). This reanalysis has a number of interesting properties, most striking of which is that it makes features relatively unimportant in characterizing natural classes. Instead natural classes are derived from the nature of the set of universal constraints posited in OT models of phonology.

\section{The weakness of the natural class restriction}

The fundamental problem with the standard theory of natural classes is that restricting rules to refer only to natural classes has minimal empirical consequences because processes that cannot be derived by a single rule that meets this condition can be derived by sets of rules that do. For example, the vowels [i, $\mathrm{a}, \mathrm{u}]$ do not form a natural class given the vowel system shown in (2), so we would not expect to find them patterning together to the exclusion of the other vowels, as in the vowel deletion rule in (3).

(3) $\{\mathrm{i}, \mathrm{a}, \mathrm{u}\} \rightarrow \varnothing / \ldots \mathrm{V}$

The rule in (3) is excluded by the natural class restriction because it refers to an unnatural class, $[\mathrm{i}, \mathrm{a}, \mathrm{u}]$, but the process that it describes can be derived by 
three well-formed rules, as in (4). The individual sounds [i], [u], and [a] are natural classes $([\mathrm{i}]=[+$ high, - back $],[\mathrm{u}]=[+$ high, + back $],[\mathrm{a}]=[+$ low $])$ so these rules satisfy the natural class restriction. In fact, any individual sound is a natural class, so the effect of any ill-formed rule can be produced by a set of well-formed rules, applying to individual sounds if necessary.

$$
\text { (4) } \begin{aligned}
\mathrm{i} & \rightarrow \varnothing / \ldots \mathrm{V} \\
\mathrm{a} & \rightarrow \varnothing / \ldots \mathrm{V} \\
\mathrm{u} & \rightarrow \varnothing / \ldots \mathrm{V}
\end{aligned}
$$

Another example that illustrates this point involves sub-groupings of places of articulation, a problem that we will return to in section 4. In Chomsky and Halle (1968), major places of articulation were distinguished using two binary features, [anterior] and [coronal], as illustrated for bilabial, alveolar, and velar stops in (5). This system groups $[\mathrm{p}, \mathrm{t}]$ and $[\mathrm{p}, \mathrm{k}]$ as natural classes. However, the validity of such natural classes has long been questioned (e.g. Kenstowicz and Kisseberth, 1977: 248; Steriade, 1986), and some more recent feature theories, such as that proposed in Sagey (1986), do not group major places of articulation at all. In Sagey's model, labial, coronal, and dorsal consonants are specified using privative features [labial], [coronal], and [dorsal] respectively (6), so in English $[\mathrm{p}, \mathrm{t}, \mathrm{k}]$ constitutes the natural class of voiceless stops ([-sonorant, -continuant, voice]), but pairs of stops such as $[\mathrm{p}, \mathrm{t}],[\mathrm{p}, \mathrm{k}],[\mathrm{t}, \mathrm{k}]$, do not constitute natural classes since there are no features that exclusively group these pairs of places of articulation. 
(5)

$\begin{array}{cccc} & \mathrm{p} & \mathrm{t} & \mathrm{k} \\ {[\text { anterior] }} & + & + & - \\ \text { [coronal } & - & + & -\end{array}$

(6)

$\begin{array}{ccc}\mathrm{p} & \mathrm{t} & \mathrm{k} \\ \text { [labial] } & {[\text { coronal] }} & \text { [dorsal] }\end{array}$

Consequently, Sagey's feature system implies that rules must apply to all places of articulation or to only one, so we should not find rules such as (7) that voice just coronal and dorsal stops after nasals. However, this process can be derived by two well-formed rules, each applying to a natural class consisting of one segment (8).

(7) $\{\mathrm{p}, \mathrm{t}\} \rightarrow[+$ voice $] /[+$ nasal $]$

(8) $\mathrm{p} \rightarrow[+$ voice $] /[+$ nasal $]$ $\mathrm{t} \rightarrow[+$ voice $] /[+$ nasal $]$

So the natural class restriction on its own is empirically vacuous - it does not actually exclude any phonological processes. The problem is that phonological patterns are derived by a complete phonological grammar, in this case a set of rewrite rules, and restricting the power of individual rules generally has limited effects on the power of phonological grammars because processes that cannot be characterized by a single rule may still be formulated in terms of a set of rules (cf. 
Archangeli and Pulleyblank, 1994: 394; Kirchner, 1998: 130; McCarthy, 2002: 103).

This situation is unsatisfactory because there is some real empirical substance behind the natural class generalization. However the actual generalizations are not about individual rules but about processes, i.e. mappings between input and output in a language. For example, the process described by the rule in (3) is unattested. Deletion of vowels in hiatus is common, but there is no process that deletes high and low vowels before vowels, leaving mid vowels to surface in the same context. To account for this fact in a rule-based framework, it is necessary to exclude not only the rule in (3), but also any set of rules that would yield this process, such as those in (4). The process described by the rules in (7) and (8) is also unattested. Post-nasal voicing of obstruents is a widely attested process (Locke, 1983; Pater, 1996; Hayes, 1999), but none of the instances discussed in these sources is sensitive to place of articulation: if a class of obstruents (i.e. fricatives or stops) is voiced after nasals, then all members of that class are voiced, regardless of place of articulation ${ }^{1}$.

The natural class generalization is correct in that only certain classes of sounds can undergo the same structural change in the same environments, or condition a particular structural change. Sets such as [i, a, u] (in a language with mid vowels), and [e, x, n] do not constitute natural classes because they never pattern together in undergoing or conditioning processes. The vowels [i, e] do constitute a natural class in the system in (2) because there are processes in which these sounds pattern together. For example, this set of sounds conditions palatalization of preceding consonants in Russian. We will see that not all natural 
class generalizations based on standard features systems are valid when formulated in this way, but there are many cross-linguistic generalizations of this type, and it is these that a theory of natural classes must account for.

We have seen that is not possible to capture generalizations of this kind by restricting rules to refer only to natural classes because a set of input $\rightarrow$ output mappings that we would pre-theoretically regard as a single process can be analyzed in terms of multiple rules. It is also necessary to restrict the sets of rules that can cooccur in a grammar so as to rule out the rule set shown in (4). The condition on individual rules only has effects given an implicit assumption that a single process must be analyzed in terms of a single rule, but such a principle is extremely difficult to formulate precisely because the required notion of a process is ill-defined. In general, very little has been said about constraints on possible sets of rules in rule-based models of phonology².

A more satisfactory account of natural class generalizations can be formulated in terms of Optimality Theory. OT naturally allows for the formulation of a theory of possible processes because OT constraints apply to all mappings in a language (McCarthy, 2002: 92). In a rule-based framework, each rule specifies one part of the input $\rightarrow$ output mapping of a language, whereas in OT, each constraint limits all input $\rightarrow$ output mappings, and in that sense applies to all processes in a language. We will see that in OT, natural class generalizations derive from the nature of the universal set of constraints. This analysis has the surprising consequence that features are relatively unimportant in characterizing natural classes. Specifically, the standard characterization of a natural class as being a set of sounds that can be specified by a set of feature values is not valid. 
Sounds can pattern together even if they are not a natural class according to the feature-based definition, and may not pattern together as a natural class even if they can be specified by a set of feature values.

The analysis of natural class generalizations is developed in section 3 , and its consequences are explored in sections 4 and 5. The conclusions are summarized in section 6 .

\section{Deriving natural class generalizations in Optimality Theory}

The most direct OT derivation of a process that would be described by a rewrite rule of the form $\mathrm{A} \rightarrow \mathrm{B} / \mathrm{C}_{-} \mathrm{D}$ is a constraint ranking that places a markedness constraint $* \mathrm{CAD}$ above the faithfulness constraint that is violated by the mapping $A \rightarrow B$. For example, the process in (9), voicing of obstruents after nasals, can be derived from the constraint ranking in (10).

$$
\begin{aligned}
& {[\text {-sonorant }] \rightarrow[+ \text { voice }] /[+ \text { nasal }]} \\
& *[\text { +nasal }][\text {-voice, }- \text {-son }]>>\text { IDENT(voice) }
\end{aligned}
$$

The classes involved in this process are specified directly in the constraints: the markedness constraint refers to the classes of nasals and voiceless obstruents, and the lower-ranked faithfulness constraint allows the change in voicing that yields the class of voiced obstruents. However, we will see that the classes that can pattern together in processes are not limited to classes that are specified in constraints because processes can involve multiple markedness constraints. So 
restricting constraints to refer to natural classes would not derive the generalization that processes apply to natural classes.

For example, it was observed above that post-nasal voicing processes are not sensitive to place of articulation, so no language voices just labial and coronal obstruents after nasals. A natural class restriction on constraints would rule out a constraint like (11), assuming that coronal and dorsal obstruents do not constitute a natural class, as in Sagey's (1986) feature system. This makes it impossible to derive post-nasal voicing of coronals and velars via a single markedness constraint, but it does not rule out the possibility of deriving this pattern using multiple markedness constraints. That is, constraints such as *[+nasal][p] or *[+nasal][t] refer only to natural classes, since voiceless labial obstruents and voiceless coronal obstruents each constitute natural classes, and these constraints can be used to derive the unattested voicing process (12).

$*[+$ nasal $]\{\mathrm{p}, \mathrm{t}\}:$ No voiceless [labial] or [coronal] obstruents after a nasal.

$$
*[+ \text { nasal }][\mathrm{p}], *[+ \text { nasal }][\mathrm{t}]>>\operatorname{IDENT}[\text { voice }]>>*[+ \text { nasal }][\text {-son, -voice }]
$$

So the impossibility of the unattested pattern of post-nasal voicing must follow from the absence of the constraints $*[+$ nasal $][\mathrm{p}]$ and $*[+$ nasal $][\mathrm{t}]$ from the universal constraint set, but a meta-constraint restricting constraints to refer to natural classes does not have this effect. We can hypothesize that the constraints $*[+$ nasal $][\mathrm{p}]$ and $*[+$ nasal $][\mathrm{t}]$ are unmotivated because all voiceless obstruents are harder to produce than corresponding voiced obstruents in the environment 
following a nasal (Hayes, 1999; Pater, 1996), and this difficulty is not significantly affected by place of articulation.

This example provides a simple illustration of the fact that the class of sounds that undergoes a process can emerge from multiple constraints. That is, *[+nasal][p] only mentions the class of labial obstruents, while *[+nasal][t] only mentions the class of coronal obstruents, but if both outrank IDENT[voice], then it is possible to derive voicing of labial and coronal obstruents. So the possibility of deriving a natural class of labials and coronals depends on the nature of the constraint set: if labial and coronal obstruents are marked in the same context, according to one or more constraints, there can be processes that apply to both in that context. This could be due to a single constraint, as in (11), or a set of constraints, as in (12). If labials and coronals never pattern together as a natural class, it must be because there are no constraints that render them marked in the same context. This is a condition on the contents of the set of constraints.

While it is necessary to block the construction of unnatural classes from multiple constraints to derive the impossibility of processes like post-nasal voicing of just labials and coronals, we will see that natural classes are properly derived from multiple constraints in many cases, so this is an important mechanism to consider in constructing a theory of possible natural classes. We will review two examples of this kind, then consider the general conditions under which sets of sounds constitute natural and unnatural classes. 


\subsection{Natural classes in palatalization processes}

A simple example of the derivation of a natural classes from multiple constraints is provided by an aspect of the typology of palatalization processes in Slavic, discussed by Rubach (2002). In many Slavic languages, consonants are palatalized before front vowels. In some of these languages, such as Ukrainian, palatalization is only conditioned by the high front vowel [i], not by mid-front [e] (13). In other languages, such as Russian, palatalization is conditioned by both high front [i] and mid front [e] (14). But there is no language in which palatalization is conditioned by [e] and not [i]. Chen (1973) argues that this pattern reflects an implicational universal: if mid front vowels condition palatalization then so do high front vowels.

(13) Ukrainian:

brat 'brother' (nom.sg.) brat ${ }^{\mathrm{j}}$-iv (gen.pl.) brat-e (voc.sg.)

(14) Russian:

brat 'brother' (nom.sg.) brat ${ }^{\mathrm{j}}$-ik (dim.) $\quad$ brat ${ }^{\mathrm{j}}$-e (loc.sg.)

This pattern can be analyzed in terms of the two constraints shown in (15) (adapted from Rubach 2002), where PAL-i is universally ranked above PAL-e.

(15) PAL-i : A consonant must be palatalized before a high front vowel. PAL-e : A consonant must be palatalized before a mid front vowel. 
The Ukrainian and Russian patterns of patalatalization are then derived from the constraint rankings shown in (16). Chen's implicational universal follows from the fixed ranking of the two markedness constraints: if PAL-e is ranked above IDENT-C(back), then PAL- $i$ must be ranked above it also, so if [e] conditions palatalization, then [i] does so as well ${ }^{3}$.

\section{(16) Ukrainian: PAL- $i>>$ IDENT-C(back) $>>$ PAL-e Russian: $\quad$ PAL- $i>$ PAL- $e>$ IDENT-C(back)}

According to this analysis, Russian palatalization is an example of a process in which the class of conditioning segments is derived from multiple markedness constraints. High and mid front vowels pattern together in conditioning palatalization in Russian because both PAL- $i$ and PAL- $e$ rank above the relevant faithfulness constraint. No single constraint mentions the class of non-low front vowels. As Rubach argues, the use of two constraints in the analysis of Russian palatalization is motivated by the typology of palatalization processes. PAL- $i$ is motivated by the existence of languages like Ukrainian in which palatalization is conditioned by high vowels only, so an additional constraint is required to account for languages like Russian, in which mid vowels also condition palatalization. In such a language, both constraints are active.

Of course the resulting class is natural by any standards, and could be referred to directly by a constraint PAL-[-low], 'A consonant must be palatalized before a [-low, -back] vowel', in place of PAL-e (cf. Rubach 2000, fn.45). The point is that no constraint has to mention this class in order for it to figure in 
processes. The same natural class of non-low vowels can be derived whether vowel height is treated as a scalar feature with values [high], [mid], and [low], so there is no feature that groups high and mid vowels, or if vowel height is analyzed in terms of the usual pair of binary features [+/-high] and [+/-low]. That is, the system of features is not tightly constrained by the need to account for the observed natural classes because it is the nature of the PAL constraints that determines these classes.

\subsection{Natural classes in nasal deletion processes}

A more complex example of the same kind comes from the typology of nasal deletion processes. In Lithuanian, the dental nasal [n] is deleted before glides, liquids, fricatives and nasals (with compensatory lengthening of the preceding vowel if it is short) (Kenstowicz, 1972; Ambrazas, 1997). This process results in

variation in the realization of the prefix /sá:n-/, as shown in $(17)^{4}$. The dental nasal is not deleted before stops, although it assimilates in place (17a), but before other consonants it is deleted (17b). The same restrictions apply to word-final clusters: [n] can precede a stop (e.g. [sént] 'to get old'), but cannot precede a fricative, with the exception of two inflectional /-s/ suffixes which may follow a stem-final [n] (Ambrazas; 1997: 66). Word-final clusters of [n] followed by a glide, liquid or nasal are also prohibited, but this could be attributed to a more general prohibition against clusters of sonorants in word-final position. 
(17) Lithuanian (Kenstowicz, 1972: 12)

(a) No deletion of $/ \mathrm{n} /$ before stops.

\begin{tabular}{|c|c|c|c|}
\hline sá:ndora & 'covenant' & dorà & 'virtue' \\
\hline sá:ntaka & 'confluence' & teké:ti & 'to flow' \\
\hline sá:mburris & 'assembly' & buirĩis & 'crowd' \\
\hline sá:mpilas & 'stock, store' & pìlnas & 'full' \\
\hline sá:mbú:ris & 'assembly' & bu:rĩis & 'crowd' \\
\hline sá:ykaba & 'coupling, clamp' & kã:be: & 'hook' \\
\hline
\end{tabular}

(b) Deletion of $/ \mathrm{n} /$ before glides, fricatives, liquids and nasals.

\begin{tabular}{|c|c|c|c|}
\hline sá:juyga & 'union' & jùngas & 'yoke' \\
\hline sáivoka & 'idea' & vó:kti & 'understand' \\
\hline sá:skambis & 'harmony' & skambé:ti & 'ring' \\
\hline sá:Slavos & 'sweepings' & Slúoti & 'sweep' \\
\hline sá:zine: & 'conscience' & zinó:ti & 'know' \\
\hline sá:listis & 'clash, contact' & lí:ti & 'to rain' \\
\hline sá:raJas & 'list, register & rasíti & 'to write' \\
\hline sá:mokslas & 'conspiracy' & mó:kslas & 'skill' \\
\hline sá:nari:s & 'joint' & narĩ:s & 'link' \\
\hline
\end{tabular}

The class of glides, liquids, fricatives and nasals is not natural according to most feature systems. If nasals were excluded, we would have the class [+continuant, -syllabic], but nasals are [-continuant]. The sounds other than fricatives are all [+sonorant, -syllabic], but fricatives are [-sonorant]. Kenstowicz 
(1972) consequently employs a disjunction to specify the conditioning environment $(18)^{5}$.

$$
\mathrm{n} \rightarrow \varnothing /-\left\{\begin{array}{c}
{[- \text {-sonorant },+ \text { continuant }]} \\
{[\text {-syllabic },+ \text { sonorant }]}
\end{array}\right\}
$$

Consideration of comparable nasal deletion processes in other languages yields evidence that the class of segments that condition nasal deletion in Lithuanian arises from a combination of several constraints on nasal-consonant sequences. These constraints are motivated by the fact that these other languages delete nasals in subsets of the environments observed in Lithuanian. The relevant patterns of nasal deletion are summarized in table 1, showing which classes of consonants condition deletion of a preceding nasal in each language (data and references are given below).

\begin{tabular}{|l||c|c|c|c|c|}
\hline $\begin{array}{c}\text { deletion } \\
\text { before: }\end{array}$ & Lithuanian & Hungarian & Frisian & $\begin{array}{c}\text { Diola- } \\
\text { Fogny }\end{array}$ & $\begin{array}{c}\text { Bahasa } \\
\text { Indonesian }\end{array}$ \\
\hline \hline stop & & & & & \\
\hline nasal & $\checkmark$ & & & & $\checkmark$ \\
\hline fricative & $\checkmark$ & $\checkmark$ & $\checkmark$ & & \\
\hline liquid & $\checkmark$ & $\checkmark$ & $\checkmark$ & $\checkmark$ & $\checkmark$ \\
\hline glide & $\checkmark$ & $\checkmark$ & $\checkmark$ & $\checkmark$ & $\checkmark$ \\
\hline h & - & $\checkmark$ & & - & \\
\hline
\end{tabular}

Table 1. Summary of environments that condition nasal deletion. Affricates pattern with stops. $\boldsymbol{\checkmark}=$ deletion applies, - = language lacks relevant segment 
The range of nasal deletion processes summarized in table 1 can be accounted for in terms of four constraints on consonant clusters with an initial nasal (19).

Constraint:

*NAS-APPROX: *[+nasal, +cons][+son, +cont, -syll]

*NAS-FRIC: $\quad *[+$ nasal, + cons] [-son, + cont]

*NAS-h: $\quad *[+$ nasal, + cons $][\mathrm{h}]$

*NASGEM: No geminate nasals.
Sample violations:

$* \mathrm{nl}, * \mathrm{nr}, * \mathrm{nj}$

*ns, *nf

*nh, *nf

$* \mathrm{nn}$

Deletion occurs where any of the constraints in (19) rank above MAX (MAX constraints penalize the deletion of segments). In Lithuanian the dental nasal deletes but the labial nasal does not, e.g. [krimnto] 'chew ( $3^{\text {rd }}$ pers., past)', [kriñsti] 'chew (inf.)' so we will differentiate MAX constraints for each nasal, i.e. $\operatorname{Max}[\mathrm{n}], \operatorname{MAx}[\mathrm{m}]$, etc. The ranking for Lithuanian is then as shown in (20) - all the markedness constraints in (20) rank above MAX[n], but below MAX[m], so dental $[\mathrm{n}]$ is deleted in all the specified environments, but $[\mathrm{m}]$ is not (velar nasals are irrelevant because they only arise through assimilation of [n] to a velar stop).

(20) Lithuanian: MAX[m] $>>*$ NAS-APPROX, *NAS-FrIC, *NASGEM $>$ MAX[n]

The first three constraints in (19) penalize nasal stops that precede particular classes of consonants - approximants, fricatives, and [h]. The dental nasal is deleted in all these environments in Lithuanian since all the markedness 
constraints outrank MAX[n]. The fourth constraint *NASGEM accounts for deletion of nasals before nasals (17b). In Lithuanian the dental nasal assimilates in place to a following consonant (17a), so if [n] were not deleted before nasals, we would expect a geminate nasal to surface. Thus deletion can be derived via a constraint against geminate nasals which blocks this alternative. In fact Lithuanian does not allow any geminates, so we could posit a more general constraint against geminates, however the typology of geminates does provide evidence for constraints against particular classes of geminates, as proposed here (Podesva, 2000).

In this analysis of Lithuanian, the natural class of segments that triggers deletion of a preceding nasal is derived from the combined action of three constraints, *NAS-APPROX, *NAS-FRIC, and *NASGEM - no single constraint refers to the complete class of nasals, fricatives, liquids and glides. It is also significant that all of the constraints can be formulated in terms of conventional features, but the same features cannot characterize nasals, fricatives, liquids, and glides in terms of a set of feature specifications. This demonstrates that a set of sounds does not have to specifiable in this way in order to pattern as a natural class, the sounds just have to be marked in the same environment - in this case all the sounds are marked after nasals. So the range of possible natural classes is determined by the constraint set rather than the feature set.

The use of multiple constraints on nasal-C clusters in the analysis of Lithuanian is not motivated by the need to account for a problematic natural class, it is motivated by the cross-linguistic variation in the environments of nasal deletion. The constraints all operate independently in other languages, so they are 
all required to account for the observed environments of nasal deletion. This can be demonstrated by comparing the patterns of nasal deletion summarized in table 1.

*NAS-APPROX must be distinguished from *NAS-FRIC in order to account for the differences between nasal deletion in Lithuanian and Bahasa Indonesian (Lapoliwa, 1981). The Indonesian pattern of nasal deletion is illustrated from alternations in form of the prefix /məy/ in $(21)^{6}$. There are no word-final consonant clusters in Indonesian, so restrictions on nasal-consonant sequences are only visible word-medially.

(21) Bahasa Indonesian /məy/ prefix (Lapoliwa 1981:104ff.)

(a) No deletion of $/ \mathrm{y} /$ before stops, fricatives, $h$.

$\begin{array}{ll}\text { məygorey cf. } & \text { gorey 'roast' } \\ \text { məyantuk } & \text { kantuk 'be sleepy' } \\ \text { məmfitnah } & \text { fitnah 'slander' } \\ \text { məyhilay } & \text { hilay 'disappear' }\end{array}$

(b) Deletion of $/ \mathrm{y} /$ before nasals, liquids, glides.

$\begin{array}{ll}\text { mənikah cf. } & \text { nikah 'marry' } \\ \text { məlatih } & \text { latih 'train' } \\ \text { mərasa } & \text { rasa 'feel' } \\ \text { məjakin } & \text { jakin 'convince' }\end{array}$


Deletion of vowels before liquids, glides and nasals is also observed in Lithuanian, but in Lithuanian nasals are also deleted before fricatives, and this is not the case in Indonesian. Therefore these environments of deletion are typologically independent, and must be accounted for in terms of separate constraints. That is, *NAS-APPROX ranks above the relevant MAX constraint in each language, but *NAS-FRIC ranks above MAX in Lithuanian, and below it in Indonesian (22). The velar nasal assimilates in place to a following consonant, so deletion of $[\mathrm{y}]$ before nasals can be analyzed in terms of high-ranking *NASGEM, as in Lithuanian.

$$
\text { Indonesian: *NAS-APPROX, *NASGEM >> MAX[n] >> NAS-FRIC }
$$

Diola Fogny (Sapir, 1957) is similar to Indonesian: nasals assimilate in place to following stops, fricatives, and nasals (23a), but are deleted before liquids and glides (23b). The key difference from Indonesian is that nasals are deleted before nasals in Indonesian, but geminate nasals are permitted in Diola Fogny. This shows that deletion before nasals is independent of deletion before approximants so the two processes must be governed by different constraints. The constraint ranking for Diola is shown in (24). A similar distribution of nasals in clusters is found in Latin: nasals can precede stops, fricatives and nasals in medial clusters, but may not precede liquids or glides (Devine, 1977). 
(23) Diola Fogny (Sapir, 1957).

(a) No deletion of nasals before stops, fricatives, nasals.

$\begin{array}{lll}\text { /ni-gam-gam/ } \rightarrow & \text { nigangam } & \text { 'I judge' } \\ \text { /na-ti:n-ti:y/ } & \text { nati:nti:y } & \text { 'he cut (it) through' } \\ \text { /fan-fan/ } & \text { famfan } & \text { 'lots' } \\ \text { /na-mi:n-mi:n/ } & \text { nami:mmi:n } & \text { 'he cut (with a knife)' }\end{array}$

(b) Deletion of nasals before liquids, glides.

\begin{tabular}{|c|c|c|}
\hline /na-lan-lan/ & nalalan & 'he returned' \\
\hline /na-jokعn-jokعn/ & najokejoken & 'he tires' \\
\hline
\end{tabular}

(24) Diola: *NAS-APPROX >> MAXNASAL >> *NAS-FrIC, *NASGEM

Deletion before nasals is also independent of deletion before fricatives, as can be seen from a comparison between Lithuanian and Frisian (Tiersma, 1985). In Frisian, coronal [n] is deleted before fricatives, liquids, and glides, as in Lithuanian, but it is not deleted before nasals or [h] (25) (page numbers are references to Tiersma (1985)) ${ }^{7}$. The ranking for Frisian is given in (26). 
(25) Frisian (Tiersma, 1985)

(a) No deletion of $/ \mathrm{n} /$ before stops, nasals, [h].

$\begin{array}{llll}\text { /in+binə/ } & \text { imbinə } & \text { 'to bind into' } & \text { p.27 } \\ \text { /skin+də/ } & \text { skində } & \text { 'shone }\left(3^{\text {rd }} \mathrm{sg} .\right) & \mathrm{p} .143 \\ \text { /un+gəvoən/ } & \text { ujgəvoən } & \text { 'unusual' } & \mathrm{p} .27 \\ \text { /fon mem/ } & \text { fommem } & \text { 'of mother' } & \mathrm{p} .143 \\ \text { /in+heljə/ } & \text { inheljə } & \text { 'to take in' } & \mathrm{p} .16\end{array}$

(b) Deletion of $/ \mathrm{n} /$ before fricatives, liquids, glides.

$\begin{array}{llll}\text { /in+sjen/ } & \text { isjen } & \text { 'to look in' } & \text { p.15 } \\ \text { /vin+st/ } & \text { viist } & \text { 'wind (2 }{ }^{\text {nd }} \mathrm{sg.} \text { )' } & \text { p.16 } \\ \text { /in+folə/ } & \text { ifolə } & \text { 'to fall in' } & \text { p.15 } \\ \text { /in+rınə/ } & \text { ĩrınə } & \text { 'to walk in' } & \text { p.15 } \\ \text { /in+lızə/ } & \text { îlızə } & \text { 'to lie in' } & \text { p.15 } \\ \text { /in+ja:n/ } & \text { ija:n } & \text { 'to give in' } & \text { p.15 }\end{array}$

(26) Frisian: *NAS-APPROX, *NAS-FrIC >> MAX[n] >> NAS-h, *NASGEM

Incidentally, nasal deletion in Frisian also differs from the other processes considered so far in that nasalization is preserved on the preceding vowel even when the nasal is deleted (25b). This pattern can be analyzed in terms of the constraint ranking MAX[nasal] $>$ *NASALV, requiring the [+nasal] feature of the underlying nasal to be preserved even at the cost of creating a nasalized vowel. In 
the other languages discussed so far this ranking is reversed (*NASALV >> MAX[nasal]) so nasalization is not preserved on vowels when nasals are deleted.

The comparison between Frisian and Hungarian provides evidence for the final constraint, *NAS-h, because nasal deletion applies in the same environments in both languages except that $/ \mathrm{n} /$ deletes before $[\mathrm{h}]$ in Hungarian, but not in Frisian. So *NASAL-h is ranked above MAX[n] in Hungarian (27), but below it in Frisian (26). Note that deletion of $/ \mathrm{n} /$ before $[\mathrm{h}]$ is not a consequence of a general ban on Ch clusters - many clusters of this type are well-formed, e.g. [mailfi] 'pack', [morfo] 'cattle', [naitho] 'flue' (Siptár and Törkenczy, 2000: 129f., 137) (/h/ is realized as voiced [h] between sonorants (p.274)).

$$
\text { Hungarian: *NAS-APPROX, *NAS-FrIC, *NAS-h >> MAX[n] >> *NASGEM }
$$

The Hungarian pattern is illustrated in (28). Nasal deletion is optional, but usual in the standard dialect (Kiss, 2002). Nasalization remains on the preceding vowel, which is also lengthened if underlyingly short (as in [tõ:fiol] 'tuna').

(28) Hungarian (Siptár and Törkenczy, 2000:208ff., Kiss, 2002)

(a) No deletion of $/ \mathrm{n} /$ before stops and nasals.

$$
\begin{array}{lll}
\text { /gond/ } & \text { gond } & \text { 'anxiety' } \\
\text { /tfonk/ } & \text { tfonk } & \text { 'stump' } \\
\text { /ojon mogos/ } & \text { ojommogos } & \text { 'so high' }
\end{array}
$$


(b) Deletion of nasals before fricatives, liquids, glides, [h].

$\begin{array}{lll}\text { /i:nje:g/ } & \text { i:je:g } & \text { 'misery' } \\ \text { /pe:nz/ } & \text { pẽ:z } & \text { 'money' } \\ \text { /ki:nlo:dik/ } & \text { kĩ:lo:dik } & \text { 'be in pain' } \\ \text { /by:njel/ } & \text { bỹ:jel } & \text { 'corpus delicti' } \\ \text { /tonhol/ } & \text { tõ:fol } & \text { 'tuna' }\end{array}$

These analyses illustrate the derivation of natural classes from a set of similar constraints. The cross-linguistic typology of nasal deletion processes motivates multiple constraints on Nasal-C clusters, each of which can drive nasal deletion. Nasal deletion processes with different classes of conditioning segments are derived by ranking MAX constraints with respect to the Nasal-C constraints. The class of segments that conditions deletion of a preceding nasal is derived from the combined action of all of the constraints that are ranked above MAX. So a set of sounds can pattern together as a natural class if they are referred to by a single constraint, e.g. approximants can pattern as a natural class given the existence of constraints like *NAS-APPROX, but a set of sounds can also form a natural class if they are marked in the same environment according to multiple constraints. Nasals, fricatives, liquids, and glides pattern together in Lithuanian because all of these sounds are marked after nasals. That is, there are constraints against each of these sound types following a nasal. It is this property of being marked in the same environment that makes a set of sounds a possible natural class. From this it follows that the range of possible natural classes is derived from the nature of the constraint set, not from the nature of the feature set. 
If the four Nasal-C constraints were freely rankable, we would derive fifteen natural classes by ranking each possible subset of the four above MAX. We have only seen five of these rankings, which could indicate that some of the rankings between Nasal-C constraints are fixed universally, or that there are more patterns of nasal deletion to be identified. For example, if we posit the fixed rankings *NAS-APPROX $>$ *NAS-FRIC and *NAS-FRIC $>$ *NAS-h then we derive just the five patterns described above, plus a pattern in which nasals are deleted before nasals, fricatives, liquids, glides and [h] - i.e. like Frisian, but with a restriction against geminate nasals. However there may well be more patterns of nasal deletion. There are certainly processes in which nasals are deleted only before fricatives: in the development of Old English and Old Frisian, nasals where deleted before voiceless fricatives (e.g. Jones, 1989: 21f.). This development did not occur in German, so we find correspondences between German and English such as gans-goose, funf-five. Similar examples are enumerated in Ohala and Busá (1995). However, in most such cases the only observed nasal clusters consist of a nasal followed by a stop, so it is not clear that nasal deletion is blocked before approximants. In any case, the examples of nasal deletion considered above are sufficient to illustrate the derivation of natural classes from sets of similar constraints, even if the full typology remains to be established.

We summarize the conclusions of this section by reviewing the basic conditions under which a set of sounds can pattern as a natural class. First, all members of the class must be marked in the same environment, according to one or more constraints. In the simplest case, a single constraint refers to the class, e.g. *NAS-FRIC refers to the class of nasals, so these sounds can form a natural 
class. But we have seen that natural classes are also derived from sets of similar constraints. In Lithuanian nasal deletion, glides, liquids, fricatives and nasals can form a natural class in nasal deletion because the constraints *NAS-APPROX, *NAS-FRIC, *NAS-h, and *NASGEM make all of these sound types marked following nasals. Schematically, a set of sounds $\{\mathrm{A}, \mathrm{B}, \mathrm{C}\}$ is marked in a context if there are constraints such as $* \mathrm{XA},{ }^{*} \mathrm{XB},{ }^{*} \mathrm{XC}$. Second, none of the relevant constraints can apply to any sounds outside of the class. For example, $[\mathrm{j}, 1, \mathrm{f}]$ are all marked after nasals according to the constraints *NAS-APPROX and *NAS-FRIC, but this does not make these sounds a possible natural class because those constraints also make $[\mathrm{w}, \mathrm{r}, \mathrm{s}$, etc] marked in the same environment.

A set such as $[e, x, n]$ does not pattern together as a natural class because no constraints make these sounds (and only these sounds) marked in the same context. Any constraints general enough to apply to such a disparate set of sounds will apply to other sounds as well.

These conditions refer only to the contents of the constraint set, they do not refer to feature specifications, so features play a minimal role in characterizing natural classes. This conclusion contradicts the standard account where natural classes are derived from the feature set alone. Of course sounds that are marked in the same environment often share phonetic properties because many markedness constraints have a phonetic basis, so the constraint-based analysis is consistent with the generalization that natural classes involve phonetically similar sounds, but it is the shared environment of markedness that is essential, not the shared phonetic properties. 
It is worth clarifying that this is not an argument against using sets of feature specifications to refer to classes of sounds in the formulation of constraints. As noted, constraints typically apply to classes of phonetically similar sounds so it is convenient to be able to refer to such sets succinctly, and phonetic features make this possible. The point made here is that the nature of the feature set has minimal consequences for the nature of possible natural classes because sounds do not need to be grouped together in a single constraint in order to pattern as a natural class.

\section{Limits on the generality of natural classes.}

Given that natural classes arise where constraints make a class of sounds marked in the same environment, we should expect some natural classes to arise only in a limited range of processes. For example, the Nasal-C constraints in the previous section make glides, liquids, fricatives, and nasals marked in the same context so these sounds can pattern together in conditioning deletion of a preceding nasal. But this exact set of sounds may not be marked in any other context, in which case they will not pattern together in any processes other than those driven by Nasal-C constraints. In other words, the constraint set not only yields generalizations about possible and impossible natural classes, but also about the kinds of processes in which they may figure.

It seems likely that glides, liquids, fricatives and nasals are a relatively restricted natural class, since this class is not natural according to the standard feature-based criterion (although they are grouped by some definitions of sonority as consonants that are more sonorous than plosives). In this section we consider 
the derivation of some very restricted natural classes that arise in inter-vocalic spirantization processes.

Pairs of major places of articulation are attested as natural classes in intervocalic spirantization processes (Kirchner, 1998). For example, in Dahalo (Maddieson et al, 1993) labial and coronal voiced stops are optionally spirantized between vowels, but velar stops do not spirantize (29).

$$
\begin{aligned}
& \text { dába dáßa 'hand' } \\
& \text { ná:dite ná:O্নंite 'coconut palm' } \\
& \text { kádi káoi } \text { 'work' } \\
& \text { dzá:go *dzá:yo ‘cow; }
\end{aligned}
$$

In Tibetan (Odden, 1978) labial, velar, and uvular stops are spirantized between vowels, but coronal and palatal stops are not. This process gives rise to the alternations shown in (30) when the negative prefix is added to a stop-initial stem $^{8}$. Kanuri (Lukas, 1937; Cyffer, 1998) also shows inter-vocalic spirantization of labial and velar stops, but not coronals.

(30) affirmative negative

(a) paaßaree maßaßßoree 'he lit' kuußəree məyußəree 'he waited' qээßree masэวßәree 'he took time out' 
(b) caaßree macaaßəree 'he lifted'

tfaaßəree matfaaßəree 'he went'

tããpəree matããpəree 'he sufficed'

taaßree mataaßoree 'he roasted'

In addition there are processes in which only stops at a single place of articulation undergo spirantization (Kirchner, 1998: 7): only labials spirantize in Comanche (Armagost and McLaughlin, 1992) and Nkore-Kiga (Taylor, 1985), only coronals spirantize in Purki (Rangan, 1979), and only velars spirantize in Cherokee ${ }^{10}$. This suggests that there are separate constraints against intervocalic stops for each major place of articulation (31).

$$
\begin{aligned}
& * \mathrm{~V}[\mathrm{lab}, \text {-cont }] \mathrm{V} \\
& * \mathrm{~V}[\mathrm{cor}, \text {-cont }] \mathrm{V} \\
& * \mathrm{~V}[\text { dor, } \text {-cont }] \mathrm{V}
\end{aligned}
$$

The set of stops that undergo spirantization depends on the ranking of these constraints with respect to the faithfulness constraint IDENT(continuant). For example, the rankings for Dahalo and Tibetan are as shown in (32). Since palatals pattern with coronals in resisting lenition, we must assume that they are specified [coronal], as proposed by Halle and Stevens (1979), or we must posit separate lenition constraints for palatals and other dorsals. The latter analysis would predict that palatals need not always pattern with coronals in lenition. 
a. Dahalo:

$* \mathrm{~V}[\mathrm{lab}$, -cont $] \mathrm{V}, * \mathrm{~V}[$ cor, -cont $] \mathrm{V}>>\mathrm{IDENT}($ cont $)>>* \mathrm{~V}[$ dors, -cont $] \mathrm{V}$

b. Tibetan

$* \mathrm{~V}[\mathrm{lab}$, -cont $] \mathrm{V}, * \mathrm{~V}[\mathrm{dors},-$ cont $] \mathrm{V}>>\mathrm{IDENT}(\mathrm{cont})>>* \mathrm{~V}[\mathrm{lab}$, -cont $] \mathrm{V}$

The existence of three similar constraints allows for the derivation of many natural classes of undergoers in spirantization processes. Stops at all places of articulation are marked inter-vocalically, so stops at any one, two, or three places of articulation may pattern together in undergoing spirantization in this environment. Spirantization of all places of articulation is well-attested (e.g. Mexican Spanish, Harris, 1969), and we have seen that pairs of places of articulation can undergo spirantization, although I am not aware of any straightforward examples where coronals and dorsals spirantize while labials do not $^{11}$. Given the existence of all the other patterns, this may well be an accidental gap.

The attested natural classes involving pairs of stops, i.e. labial and coronal stops in Dahalo and labial and dorsal stops in Tibetan, are not predicted by Sagey's (1986) feature theory since this system does not provide for any subgroupings of the major places of articulation, as noted in section 2. Chomsky and Halle's (1968) feature set does allow for these classes: labials and anterior coronals are [+anterior], and labials and velars are [-coronal] (although, as noted, palatals must be treated as [+coronal] to capture the Tibetan class in this way). But Chomsky and Halle's analysis of place specifications was abandoned for 
good reason-there is is little evidence for these classes or their associated features from other processes.

Kenstowicz and Kisseberth (1979:248) comment on the lack of evidence for the natural classes defined by [+anterior] and [-anterior], and Steriade (1986) argued that [anterior] should apply to coronal sounds only, a proposal that has been widely adopted. Similarly, while there is good evidence for constraints against the cooccurrence of sounds with the same major articulator cooccurring within a word (McCarthy, 1989; Mester, 1986; Padgett, 1995a; Yip, 1989), there are no languages with comparable constraints against the cooccurrence of labial and coronal consonants or labial and velar consonants. Patterns of this kind would be expected if [-coronal] were a major place feature. There is also no evidence for assimilation with respect to Chomsky and Halle's [anterior] or [coronal]. For example, given the classification of places of articulation using [anterior] and [coronal], [anterior] assimilation would be expected to yield processes such as

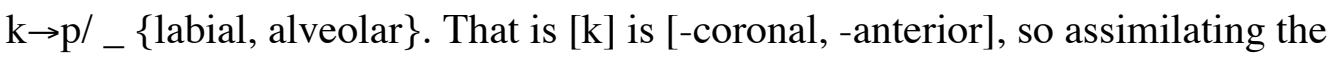
[+anterior] specification of a following labial or anterior coronal would yield a [coronal, +anterior] stop, i.e. [p]. Assimilation in [coronal] while leaving [anterior] specifications unchanged yields equally unlikely processes.

According to the analysis of natural classes developed here, labials and coronals can pattern together in spirantization processes because of the existence of the constraints $* \mathrm{~V}[1 \mathrm{ab},-$ cont $] \mathrm{V}$ and $* \mathrm{~V}[$ cor, -cont $] \mathrm{V}$ which make labial and coronal stops marked in the same environment. Violations of both constraints can be eliminated by spirantization, so labial and coronal stops are a possible natural class. This analysis does not imply that labials and coronals should pattern 
together in any processes that do not involve these two constraints - that will only occur if further constraints render labials and coronals marked in another context. The analysis proposed here derives natural classes from constraints, so natural classes are tied to constraints, and consequently different natural classes are expected to arise in different types of processes. Furthermore, labials and coronals can form a natural class without sharing any feature specification that excludes dorsals, so a feature like Chomsky and Halle's [anterior] is not necessary to account for this natural class. Consequently there is no reason to expect assimilation or dissimilation with respect to such a feature.

\section{Deriving natural classes via 'blocking' constraints}

In the preceding sections we have illustrated a mechanism for deriving natural classes from the combined action of similar constraints. However OT offers another mechanism for the derivation of natural classes, namely blocking of a general process by a higher-ranked markedness constraint. This mechanism can be illustrated from McCarthy's (1997) analysis of pharyngealization harmony in a southern variety of Palestinian Arabic (data from Davis, 1995). In this language, pharyngealization spreads leftwards and rightwards from a pharyngealized consonant (33a) (the underlying pharyngealized consonant is transcribed with the pharyngealizaton diacritic, and the extent of pharyngealization spread is indicated by underlining). Rightward spread of pharyngealization is blocked by high front vowels, palatal glides, and palato-alveolar consonants, a class that Davis characterizes as [+high, -back] (33b). 


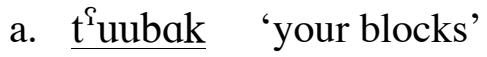

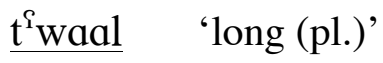
ballaas $^{\mathrm{S}}$ 'thief'
Pabsat $^{\mathrm{\Upsilon}} \quad$ 'simpler'
b. t' iinak 'your mud'

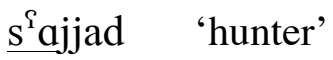
@at ${ }^{\text {f }}$ aan 'thirsty'
$\underline{\partial^{\Upsilon} \mathrm{add} z a a t}$ 'type of noise (pl.)'

McCarthy (1997) analyzes the rightward spread of pharyngealization in terms of a constraint ranking similar to (34). Following Davis (1995), pharyngealization is assumed to be specified by the feature [RTR]. RTR-RIGHT requires any instance of [RTR] to be aligned with the end of the word, motivating rightwards spread of pharyngealization. But RTR-RIGHT is ranked below a constraint against high front RTR segments, a combination which has been argued to be articulatorily difficult to produce (Archangeli and Pulleyblank, 1994). This ranking derives the blocking effect observed in (33b), as illustrated in (35). It is assumed that each segment between the [RTR] feature and the end of the word constitutes a violation of RTR-RIGHT, so RTR spreads as close to the end of the word as possible ${ }^{12}$.

$$
\text { *[RTR, +high, -back] >> RTR-RIGHT >> IDENT(RTR) }
$$

\begin{tabular}{|c|c|c|c|}
\hline$/ s^{\text {q}}$ ajjad / & $\begin{array}{l}\text { * RTR, } \\
\text { +high, } \\
\text {-back] }\end{array}$ & $\begin{array}{l}\text { RTR- } \\
\text { RIGHT }\end{array}$ & $\begin{array}{l}\text { IDENT } \\
\text { (RTR) }\end{array}$ \\
\hline$\underline{\underline{s}}^{\mathrm{S}}$ ajjad & & $* * * * * !$ & \\
\hline s $^{\Upsilon} a j j a d$ & $* !$ & & $* * * *$ \\
\hline$\underline{s}^{s} a j j a d$ & & ***** & $*$ \\
\hline
\end{tabular}


The result of this constraint ranking is a process in which the rightward spread of pharyngealization targets all segments that are not [-high, -back]. This class is derived from the interaction of RTR-RIGHT, which targets all segments, and *[RTR, +high, -back] which blocks a subset of segments from undergoing pharyngealization (35). The resulting class of segments is decidedly unnatural according to the standard theory - the set of segments that are not [+high, -back] cannot be characterized in terms of a set of feature specifications. Davis's (1995) rule-based analysis also does not refer directly to the class of non-[+high, -back] sounds - the process is analyzed in terms of a general rule of pharyngealization harmony which is subject to the constraint that it cannot create the feature combination [RTR, +high, -back] (cf. Cohn, 1989; Archangeli and Pulleyblank, 1989 for comparable analyses of blocking in other harmony processes).

In general terms, blocking analyses allow for the derivation of natural classes that are the complement of the class mentioned by the blocking constraint. That is, the class of segments that undergoes pharyngealization harmony is the complement of the class [+high, -back] that is referred to in the constraint *[RTR, +high, -back]. The Palestinian Arabic example and other cases of blocking in harmony (e.g. Walker, 1998) show that this mechanism is well-motivated although it can derive classes that are unnatural according to the standard featurebased criterion. However, it is necessary to constrain the possibilities for blocking in order to derive correct natural class generalizations. The potential for problematic blocking interactions will be illustrated from the analysis of a natural class generalization relating to post-nasal voicing, introduced in section 1 . 
The generalization is that if stops at one place of articulation are subject to post-nasal voicing, then stops of all places of articulation undergo the same process. This is more specific than the usual natural class generalizations in that it does not specify that a class cannot pattern together under any circumstances, instead it is a generalization about the classes of segments that can undergo a particular process. However, generalizations of this kind are derived in much the same way as standard natural class generalizations, and can actually involve more stringent restrictions on the constraint set.

The constraint set must obey several restrictions in order to derive the generalization. First, there must be a single constraint that applies to all of the natural class that undergoes the process, i.e. a constraint that bans all voiceless obstruents after nasals, regardless of place of articulation (36) (Pater, 1996; Hayes, 1999).

$$
\text { *NT: *[+nasal][-sonorant, -voice] }
$$

Second, as noted in section 3, there must not be any markedness constraints against any subset of the class occurring in the relevant context. That is there must not be any constraints such as $*[+$ nasal $][\mathrm{p}]$, or $*[+$ nasal $][\mathrm{t}]$, otherwise the ranking $*[+$ nasal $][\mathrm{p}]>>$ IDENT[ $[$ voice $] \gg *$ NT could derive the unattested process where only labial stops are voiced after nasals.

Finally, there must be no markedness constraints against any subset of the outputs of the process, that is no constraints such as $* \mathrm{~b}, * \mathrm{~d}$, or $* \mathrm{~g}$, against voiced stops at particular places of articulation. Otherwise these constraints could serve 
to block post-nasal voicing at particular places of articulation. For example, the ranking in (37) would derive post-nasal voicing of labials and coronals only, as illustrated in (38). In other words, this is an undesirable instance of blocking.

$$
* \mathrm{~g}>\text { *NT }>\text { IDENT[voice] }
$$

(38) An unattested pattern of post-nasal voicing.

i. Non-velar stops are voiced after nasals.

\begin{tabular}{|c|c|c|c|c|}
\hline \multirow[b]{2}{*}{ a. } & $-m p-$ & $* g$ & $* \mathrm{NT}$ & $\begin{array}{l}\text { IDENT } \\
\text { (voice) }\end{array}$ \\
\hline & $\mathrm{mp}$ & & $* !$ & \\
\hline b. & $\mathrm{mb}$ & & & $*$ \\
\hline
\end{tabular}

ii. Velar stops remain voiceless after nasals.

\begin{tabular}{|rr||c|c|c|}
\hline \multicolumn{2}{|c||}{$-\mathrm{yk}-$} & $* \mathrm{~g}$ & $* \mathrm{NT}$ & $\begin{array}{c}\text { IDENT } \\
\text { (voice) }\end{array}$ \\
\hline \hline $\mathrm{a}$ & $\mathrm{yk}$ & & $*$ & \\
\cline { 2 - 5 } $\mathrm{b}$ & $* !$ & & $*$ \\
\hline
\end{tabular}

This example makes two interesting points. The first is that the generalization about the classes of segments that can undergo post-nasal voicing is derived from the contents of the constraint set - i.e. it follows from the existence and nonexistence of particular potential constraints. Again, no strong assumptions about features are required, although it is convenient to be able to refer to the classes of nasals and voiceless obstruents succinctly so *NT can be given a simple formulation. Second, one of the proscribed constraints, ${ }^{*} \mathrm{~g}$, has been proposed by a number of researchers, including McCarthy and Prince (1995), Itô and Mester (1997), and Hayes (1999). Hayes (1999) proposes that this constraint accounts for 
the existence of languages which have stop voicing contrasts, but lack voiced velar stops (Sherman, 1975; Locke, 1983), e.g. Thai (39).

(39) Thai stops: $\begin{array}{lll}\mathrm{p} & \mathrm{t} & \mathrm{k} \\ & \mathrm{p}^{\mathrm{h}} \mathrm{t}^{\mathrm{h}} & \mathrm{k}^{\mathrm{h}} \\ & \mathrm{b} & \mathrm{d}\end{array}$

The Thai pattern could be derived by the constraint ranking $*_{\mathrm{g}}>>$ IDENT(voice) $>>*$ [-son, +voice $]$. That is, IDENT(voice) outranks the general constraint against voiced obstruents, so stop voicing contrasts are possible, but top-ranked $* \mathrm{~g}$ prevents the realization of voiced velar stops. There is also a plausible aerodynamic explanation for a particular dispreference for voicing velar stops (Ohala 1983) (see below for discussion). However we cannot postulate a constraint $* \mathrm{~g}$ without predicting an unattested pattern of post-nasal voicing.

Constraints like ${ }^{*} \mathrm{~g}$ can give rise to a wide range of blocking effects because they are very general: *g applies to any voiced velar stop regardless of its position. This context-free constraint against voiced velar stops is not motivated by Ohala's (1983) phonetic explanation for the dispreference for this type of sound. Voicing is difficult to maintain during stops because pressure builds up in the oral cavity behind the stop closure. When pressure in the oral cavity approaches pressure below the glottis, then airflow through the glottis ceases, and voicing ceases. Voicing is particularly difficult to maintain during a velar stop because the closure is relatively near to the larynx, so the volume of the vocal tract behind the closure is smaller than in labials or coronals. This means that oral 
pressure builds up faster, and that there are fewer possibilities for expansion of the cavity behind the closure (Ohala, 1983; Westbury and Keating, 1986). But the situation is rather different for a voiced stop following a nasal. In this context, the velum is typically at least partially open through most of the duration of the nasalstop cluster, so air is vented through the nose, and the rise in oral pressure is minimal. This, together with other mechanisms detailed by Hayes (1999), makes stop voicing following a nasal easy to produce, regardless of place of articulation. So a constraint against voiced velar stops should not apply to velars following nasals.

There are two possible approaches to limiting the scope of the *g constraint. One is to represent the fact that voiced stops following nasals are partially nasalized. The constraint $* \mathrm{~g}$ could then be restricted to apply only to fully oral voiced velar stops. The other approach is to make the constraint against voiced velars specific to contexts where there is no preceding nasal consonant. The latter constraint is most easily formulated as a requirement that voiced velar stops should be preceded by a nasal consonant (40) since it must penalize initial voiced velar stops as well as voiced velar stops following oral sounds. For present purposes, the key is that neither of these constraints is violated by a velar stop following a nasal, so neither constraint can block post-nasal voicing.

(40) NASAL[g]: 'voiced velar stops must be preceded by a nasal consonant'.

It should be noted that this line of reasoning suggests that any context-free constraint against voiced obstruents is an over-simplification since voiced 
obstruents are not difficult to produce in all environments. In fact, context-free segmental markedness constraints are difficult to motivate on phonetic grounds in

general, since effort and perceptual distinctiveness are generally highly dependent on context (cf. Westbury and Keating, 1986: 148f.). Constraints that are highly general and context-free are also most likely to be able to derive a wide range of natural classes through blocking interactions, so the implications of constraints of this type have to be examined carefully.

\section{Summary}

This paper has reconsidered the analysis of the generalization that only certain sets of sounds (natural classes) pattern together in phonological processes. The standard account of this generalization attempts to derive it by imposing a restriction on the sets of sounds that can be referred to in rules: sets of sounds can only be referred to if they can be specified by a conjunction of feature values. We have seen that this account is inadequate because processes can be derived from multiple rules $(\S 2)$, or from the interaction of rules and constraints $(\S 5)$, so restrictions on the sets of sounds that can be referred to in rules do not translate into restrictions on the sets of sounds that are predicted to pattern together in processes. Translating this feature-based analysis of natural classes into OT by restricting constraints to refer only to sets of feature specifications is no more effective because processes not only can be derived from multiple constraints, but often have to be derived in this way in order to account for typological generalizations $(\S 3)$. 
In OT phonology it is straightforward to derive restrictions on the sets of sounds that can pattern together in processes, but the restrictions follow from the nature of the set of universal constraints, not from the feature set. Sounds can pattern together if they are marked in the same environment according to one or

more constraints (§3). Further natural classes can be derived by 'blocking' - that is, a higher-ranked constraint can prevent a subset of a class from undergoing a process (§5). This constraint-based analysis of natural classes relieves features of the burden of accounting for natural classes. The key remaining function of features is to represent all phonetic properties that are relevant to the formulation of phonological constraints.

\section{Acknowledgements}

I would like to thank audiences at the Stanford Phonology Workshop and the University of California at Berkeley for comments at the early stages of the research reported here, and an anonymous reviewer for helpful comments on this paper. 


\section{References}

Ambrazas, V. (ed.),1997. Lithuanian Grammar. Baltos Lankos, Vilnius.

Archangeli, D., Pulleyblank, D.,1989. Yoruba vowel harmony. Linguistic Inquiry 20, 173-217.

Archangeli, D., Pulleyblank, D.,1994. Grounded Phonology. MIT Press, Cambridge, MA.

Armagost, J.L., McLaughlin, J.E., 1992. Taps and spirants in Numic languages. Anthropological Linguistics 34, 277-292.

Chen, M.,1973. Predictive power in phonological description. Lingua 32, 173191.

Chomsky, N., Halle, M.,1968. The Sound Pattern of English. Harper and Row, New York.

Cohn, A., 1990. Phonetic and Phonological Rules of Nasalization. PhD dissertation, University of California, Los Angeles.

Cyffer, N.,1998. A sketch of Kanuri. Rüdiger Köppe Verlag, Köln.

Davis, S.,1995. Emphasis spread in Arabic and grounded phonology. Linguistic Inquiry 26, 465-498.

Davis, S., 1998. Syllable contact in Optimality Theory. Journal of Korean Linguistics 23, 181-211.

Devine, A., 1977. Two Studies in Latin Phonology. Anma Libri, Saratoga, CA.

Gouskova, M., 2002. Relational hierarchies in OT. In: Mikkelsen, L., Potts, C. (Eds.), Proceedings of the West Coast Conference in Linguistics 21, pp. 113126. 
Halle, M., Stevens, K., 1979. Some reflections on the theoretical bases of phonetics. In: Lindblom, B., Öhman, S. (Eds.), Frontiers of Speech Communication Research. Academic Press, New York.

Hayes, B., 1999. Phonetically driven phonology: the role of Optimality Theory and inductive grounding. In: Darnell, M., Moravcsik, E., Newmeyer, F., Noonan, M., and Wheatley, K. (Eds.) Functionalism and Formalism in Linguistics, Volume I: General Papers. John Benjamins, Amsterdam, pp. 243-285

Itô, J., Mester, A., 1997. Correspondence and compositionality: The Ga-gyo variation in Japanese phonology. In: Roca, I. (Ed.), Derivations and Constraints in Phonology. Oxford University Press, Oxford, pp.419-462.

Jones, C., 1989. A History of English Phonology. Longman, London, UK.

Kenstowicz, M., 1972. Lithuanian phonology. Studies in the Linguistic Sciences $2.2,1-85$.

Kenstowicz, M., Kisseberth, C., 1977. Generative Phonology. Academic Press, New York.

Kirchner, R., 1998. An Effort-Based Approach to Consonant Lenition. PhD dissertation, University of California, Los Angeles.

Kiss, Z., 2002. Complexity effects in nasal-continuant clusters. The Even Yearbook 5, 57-76.

Locke, J.L., 1983. Phonological Acqusition and Change. Academic Press, New York.

Lukas, J., 1937. A Study of the Kanuri Language. Oxford University Press, Oxford [reprinted by Dawson of Pall Mall, London, 1967]. 
Macaulay, M.A., 1996. A Grammar of Chalcatongo Mixtec. University of California Press, Berkeley, CA.

Maddieson, I., Spajic, S., Sands, B., Ladefoged, P., 1993. Phonetic Structures of

Dahalo. UCLA Working Papers in Phonetics 84, 25-66.

McCarthy, J.J., 1988. Feature geometry and dependency: A review. Phonetica 43, 84-108.

McCarthy, J.J., 1997. Process-specific constraints in Optimality Theory. Linguistic Inquiry 28, 231-251.

McCarthy, J.J., 2002. A Thematic Guide to Optimality Theory. Cambridge University Press, Cambridge.

McCarthy, J., Prince, A., 1995. Faithfulness and reduplicative identity. In Beckman, J., Urbanczyk, S., Walsh, L. (Eds.), University of Massachusetts Occasional Papers in Linguistics 18. Graduate Linguistic Student Association, Amherst, MA, pp. 385-420.

Mester, A., 1986. Studies in Tier Structure. PhD dissertation, University of Massachusetts, Amherst [published by Garland Press, New York, 1988].

Nivens, R., 1992. A lexical phonology of West Tarangan. In: Burquest, D.A., Laidig, W.D. (Eds.), Phonological Studies in Four Languages of Maluku. Summer Institute of Linguistics and University of Texas at Arlington publications in Linguistics, Arlington, Texas, pp. 127-227.

Odden, D., 1978. Further evidence for the feature [grave]. Linguistic Inquiry 9, 141-144. 
Ohala, J.J., 1983. The origins of sound patterns in vocal tract constraints. In: MacNeilage, P.F. (Ed.), The Production of Speech. Springer-Verlag, New York, pp. 189-216.

Ohala, J.J, Busá, M.G., 1995. Nasal loss before voiceless fricatives: a perceptually-based sound change. Rivista di Linguistica 7, 125-144.

Padgett, J., 1995a. Stricture in Feature Geometry. CSLI Publications, Stanford, CA.

Padgett, J., 1995b. Feature classes. J. Beckman, L. Walsh Dickey, and S. Urbanczyk (Eds.) University of Massachusetts Occasional Papers in Linguistics 18. Graduate Linguistic Student Association, Amherst, MA, pp. $385-420$.

Pater, J., 1996. Austronesian nasal substitution and other NC effects. R. Kager, H. van der Hulst, and W. Zonneveld (eds) The Prosody-Morphology Interface. Cambridge University Press, UK.

Podesva, R., 2000. Constraints on geminates in Buginese and Seyalarese. Proceedings of the West Coast Conference on Formal Linguistics 19, 343356.

Prince, A., Smolensky, P., 1993. Optimality Theory: Constraint Interaction in Generative Grammar. To appear: MIT Press, Cambridge, MA.

Rangan, K., 1979. Purki Grammar. Central Institute of Indian Languages, Mysore.

Rubach, J., 2002. An overview of palatalization-i. Studies in Phonetics, Phonology and Morphology 8, 169-186. 
Sagey, E., 1986. The representation of features and relations in nonlinear phonology. PhD dissertation, MIT, Cambridge, MA [published by Garland Press, New York, 1990].

Sapir, 1965. A grammar of Diola Fogny. Cambridge University Press, Cambridge.

Sherman, D., 1975. Stop and fricative systems: a discussion of paradigmatic gaps and the question of language sampling. Working Papers on Language Universals 17,1-33.

Siptár, P., Törkenczy, M., 2000. The phonology of Hungarian. Oxford University Press, Oxford.

Steriade, D., 1986. A note on coronal. Ms., Massachusetts Institute of Technology, Cambridge, MA.

Steriade, D., 1997. Phonetics in phonology: the case of laryngeal neutralization. UCLA Working Papers in Linguistics 3, 25-146.

Taylor, C., 1985. Nkore-Kiga. Croom Helm, London.

Tiersma, P., 1980. The Lexicon in Phonological Theory. PhD dissertation, University of California, San Diego. Distributed by Indiana University Linguistics Club, Bloomington, IN.

Tiersma, P., 1985. A grammar of Frisian. Foris, Dordrecht.

Venneman, T., 1988. Preference Laws for Syllable Structure and the Explanation of Sound Change: With Special Reference to German, Germanic, Italian, and Latin. Mouton de Gruyter, Berlin.

Walker, R., 1998. Nasalization, Neutral Segments, and Opacity Effects. PhD dissertation, University of California, Santa Cruz. 
Westbury, J., Keating, P.A., 1986. On the naturalness of stop consonant voicing. Journal of Linguistics 22, 145-66.

Yip, M., 1989. Feature geometry and cooccurrence restrictions. Phonology 6, 349-374. 
Notes.

${ }^{1}$ Locke (1983) reports Mixtec as an example of place-specific post-nasal voicing, but detailed descriptions of Mixtec languages such as Macaulay (1996) do not describe such a process. Possibly this report derives from a misinterpretation of the pre-nasalized stops in this language.

${ }^{2}$ Archangeli and Pulleyblank (1994: 394ff.) is a rare exception.

${ }^{3}$ A reviewer asks about the role of fixed rankings in the theory of natural classes.

The fixed ranking proposed by Rubach does not play any role in deriving the natural class of high and mid front vowels - this class is derived by ranking PAL- $i$ and PAL-e above IDENT-C(back). The fixed ranking prevents the derivation of a palatalization process conditioned by mid vowels only. Universally fixed rankings can limit the natural classes predicted by a set of markedness constraints (see $\S 3.2$ for further exemplification of this point).

${ }^{4}$ Accents are transcribed using the orthographic symbols. All accented vowels are stressed. ['] marks a 'sharp falling toneme' and [ ] marks a 'smooth rising toneme'. ['] marks the falling toneme when placed over [ui] or [u, i] $+[1, \mathrm{~m}, \mathrm{n}, \mathrm{r}]$, in other positions it marks a short stressed vowel (Ambrazas, 1997:13f.). Allophonic palatalization before front vowels is not transcribed.

${ }^{5}$ A reviewer suggests that the Lithuanian facts might be accounted for in terms of sonority sequencing constraints. That is [n] is only retained before the least sonorous consonants (stops), which might be analyzed as resulting from a requirement for a large drop in sonority in the relevant clusters. However Lithuanian does not in general require a sonority drop in medial clusters-for 
example [-ln-] and [-pt-] clusters are acceptable: [pílnas] 'full', [sla:ptas] 'secret'. Medial stop-nasal clusters (i.e. rising sonority clusters) are also acceptable, e.g. [skobnis] 'table', and are plausibly heterosyllabic (Steriade, 1997).

Furthermore, nasal deletion applies to medial clusters, which would be heterosyllabic, and to final clusters, which would be tautosyllabic, so the sonority drop requirement would have to apply to both heterosyllabic and tautosyllabic clusters, but standard sonority sequencing constraints apply only within the syllable, while syllable contact constraints (Venneman, 1988; Davis, 1998; Gouskova, 2002) apply only to heterosyllabic clusters. More generally, there is no evidence that nasal deletion is sensitive to syllable structure in any of the languages discussed here. That is, the restrictions on medial nasal-C clusters also apply to final clusters, as far as can be determined (most languages disallow word-final sonorant-sonorant clusters, so it is not possible to find evidence for a more specific constraint against nasal-approximant sequences, and Indonesian does not allow any final clusters).

${ }^{6}$ Voiceless stops delete after the /məy/ prefix (21a) - see Pater (1996) for a recent analysis.

${ }^{7}$ Some of the final schwas are missing from Tiersma (1985: 15). The presence of the schwas is indicated by the orthography, and by transcriptions of the same words in Tiersma (1980: 15).

${ }^{8}$ Spirantization is blocked if the preceding vowel is nasalized, hence the unlenited [p] in [matããpəree] 'he sufficed'. The nasalized vowels historically developed 
from loss of post-vocalic [n], so this could arise from an opaque interaction between nasal deletion and spirantization.

${ }^{9}$ Although it appears that the voiced coronal stop is lenited to [r] or [I] except after [n] (Taylor, 1985: 200f.).

${ }^{10}$ Based on my own work with a native speaker of Oklahoma Cherokee.

${ }^{11}$ Kirchner (1998) cites West Tarangan (Nivens, 1992) as an example of this pattern. In West Tarangan [g] and [dz] are in complementary distribution with [w] and [j] respectively, a pattern that can be interpreted as involving lenition of the stops. However coronal [d] fails to undergo lenition as well as labial [b].

${ }^{12}$ It is also necessary to assume that some undominated constraint prevents RTR harmony from skipping over segments (so [s $\mathrm{s}^{\mathrm{q}} \mathrm{ajj}$ ad] is not a viable candidate), e.g. NoGAP (Padgett, 1995b; cf. Archangeli and Pulleyblank, 1994). 